\title{
Ophthalmological outcomes of unilateral coronal synostosis in young children
}

\author{
Wen-Ting Luo ${ }^{\dagger}$, Xin Chen ${ }^{\dagger}$, Yi-Dan Zhang, Qing-Yu Liu and Tong Qiao* (i)
}

\begin{abstract}
Background: To report refractive outcomes, describe types of strabismus and evaluate the outcomes of surgical intervention for unilateral coronal synostosis (UCS) in paediatric patients.

Methods: This study retrospectively included 30 UCS cases. Patients aged from 3 months to 6 years (median: 1.8 years) were enrolled from January 2018 to December 2019 at Shanghai Children's Hospital. Sixteen patients had all types of strabismus; 15 of these patients underwent surgery.

Results: Refractive errors of 30 cases were included. In $60 \%$ of patients, astigmatism of $1.00 \mathrm{D}$ or more existed in not less than one eye at last record. Twenty (66.7\%) patients had the larger amount of astigmatism in the contralateral eye. Fifteen patients received strabismus surgery, of whom 6 patients with monocular elevation deficiency (MED) underwent the standard Knapp procedure, with or without a horizontal deviation procedure. Fifteen cases were horizontally aligned within 5 prism dioptres $(\Delta)$. Six patients with MED (100\%) had attained $\geq 25 \%$ elevation improvement after surgery, and the vertical deviation decreased from $25.83 \Delta \pm 4.92 \Delta$ (range, $20 \Delta-30 \Delta$ ) to 0.83 $\Delta \pm 4.92 \Delta$ after surgery (range, $0 \Delta-10 \Delta$ ), for an improvement of $26.67 \Delta \pm 4.08 \Delta(t=16 P<0.05)$. In 1 patient with esotropia, the horizontal deviation decreased from $+80 \Delta$ to $+5 \Delta$ after surgery. One patient was diagnosed with trichiasis and one with contralateral lacrimal duct obstruction.

Conclusions: Contralateral MED was also the main type of strabismus in UCS. Superior oblique muscle palsy was still the most common, as previously reported. There is a risk of developing a higher astigmatism and anisometropia in the contralateral eye to synostosis. Other ophthalmic disorders should be treated in a timely manner.

Trial registration: The study was approved by the Institutional Review Board of Shanghai Children's Hospital (approval No. 2020R023-E01) and adhered to the tenets of the Declaration of Helsinki. Ethics approval was procured on March 30, 2020. This was a retrospective study. Written informed consent was sought from the patients' parents or legal guardians. Clinical Trials Registry number: ChiCTR2000034910.

Registration URL: http://www.chictr.org.cn/showproj.aspx?proj=56726.

(Continued on next page)
\end{abstract}

\footnotetext{
* Correspondence: Qiaojoel@163.com

Wen-Ting Luo is the first author of this manuscript.

${ }^{\dagger}$ Wen-Ting Luo and Xin Chen are equal contributors.

Shanghai Children's Hospital, Shanghai Jiao Tong University, Shanghai

200062, China
}

(c) The Author(s). 2020 Open Access This article is licensed under a Creative Commons Attribution 4.0 International License, which permits use, sharing, adaptation, distribution and reproduction in any medium or format, as long as you give appropriate credit to the original author(s) and the source, provide a link to the Creative Commons licence, and indicate if changes were made. The images or other third party material in this article are included in the article's Creative Commons licence, unless indicated otherwise in a credit line to the material. If material is not included in the article's Creative Commons licence and your intended use is not permitted by statutory regulation or exceeds the permitted use, you will need to obtain permission directly from the copyright holder. To view a copy of this licence, visit http://creativecommons.org/licenses/by/4.0/ The Creative Commons Public Domain Dedication waiver (http://creativecommons.org/publicdomain/zero/1.0/) applies to the data made available in this article, unless otherwise stated in a credit line to the data. 
(Continued from previous page)

Keywords: Unilateral coronal synostosis, Superior oblique muscle palsy, Monocular elevator deficiency, Forced duction test, Standard Knapp procedure

\section{Background}

Unilateral coronal synostosis (UCS) is the premature fusion of one coronal suture, is also known as anterior or frontal synostotic plagiocephaly, and is rare, with an incidence of $1 / 10,000$ live births [1]; in addition, UCS is the third most common type of simple craniosynostosis, preceded by involvement of the sagittal and metopic sutures [2]. UCS alters orbital development and predisposes patients to ocular disorders such as strabismus, astigmatism, and amblyopia [3, 4]. It is highly recommended that all patients who suffer from craniosynostosis be regularly examined by an ophthalmologist at the time of diagnosis and before and after craniofacial surgery [5]. The purpose of this investigation was to describe the strabismus and evaluate the outcome of surgical treatment. Another purpose of the study was to characterize the refractive error and other ophthalmic diseases in UCS patients.

\section{Methods}

This was a retrospective cohort study based on ophthalmic data of patients with UCS recorded at the Department of Ophthalmology, Shanghai Children's Hospital. All patients had radiographically confirmed UCS. Any patients with additional synostosis or other craniofacial abnormalities were excluded.

UCS was diagnosed on the basis of the clinical ophthalmic manifestation: recession and elevation of the ipsilateral superior orbital margin, elevation of the ipsilateral eyebrow and eyelid with contralateral ptosis $[2,6]$.

We reviewed 30 patients aged from 3 months to 6 years (median 1.8 years) who underwent UCS surgery at the Cerebral Department between 2017 and 2019 . All patients had radiographically confirmed UCS. Inclusion criteria required a complete medical history, surgical treatment by fronto-orbital advancement (FOA) [4] and regular post-operative ophthalmological examinations. Patients were excluded for syndromic diagnosis, multi-suture coronal synostosis involvement, previous outside interventions, and incomplete ophthalmological follow-up.

Cycloplegic refractions were performed after coronal synostosis surgery. The coordinating technician administered drugs in the following manner: each eye received 5 drops of tropicamide phenylephrine $0.5 \%$, and each drop was separated by $5 \mathrm{~min}$. Cycloplegic refractions were obtained $30 \mathrm{~min}$ after instillation of tropicamide.

Demographics, cycloplegic refraction, ocular motility, and records of craniofacial and ophthalmic operations were referred during each clinic visit. Amblyopia was defined as a fixation preference. "Ipsilateral" and "contralateral" referred to the side of coronal synostosis.

All refractions were converted to the minus cylinder prescription. The axis of the cylindrical component was categorized as 'with the rule' if the minus cylinder axis $180^{\circ} \pm 15^{\circ}$, as 'against the rule' if it was $90^{\circ} \pm 15^{\circ}$, or as oblique if it was $45^{\circ} \pm 15^{\circ}$. Aniso-astigmatism was calculated for each patient as the absolute value of the minus cylinder of the ipsilateral eye minus the contralateral eye, despite the axis. Spherical anisometropia was considered the difference between binocular spherical equivalent.

Sixteen UCS patients with strabismus were recruited from Shanghai Children's Hospital. One of 16 strabismus patients had not been offered the procedure because he had not yet reached the appropriate age for surgery. Fifteen strabismus patients aged from 1 year and 7 months to 6 years (median 2.7 years), including 10 males and 5 females, underwent procedures from January 2018 to December 2019. Due to an age not reaching the indication for operation, another strabismus patient did not receive the procedure. Six patients were diagnosed with monocular elevation deficiency (MED), their forced duction test (FDT) results were negative, and they underwent the standard Knapp procedure (Fig. 1a and b), with or without a horizontal deviation procedure (Fig. 1c). One patient was diagnosed with severe esotropia and underwent bilateral medial rectus recession. Due to the presence of congenital esotropia, vertical deviation was difficult to examine before the procedure. The possibility of concealed vertical deviation could not be ruled out. Only one of the patients seemed to have mainly horizontal deviation, and the remaining patients primarily had vertical deviation. Seven of 15 patients had congenital superior oblique palsy in at least one eye. Five of 7 patients were diagnosed with V pattern strabismus. Six patients were diagnosed with MED. One patient with trichiasis underwent a trichiasis procedure. One patient with contralateral congenital lacrimal obstruction underwent a probing operation.

Neutralizing prisms were held in front of each paralysed eye to measure the primary deviation. The level of 


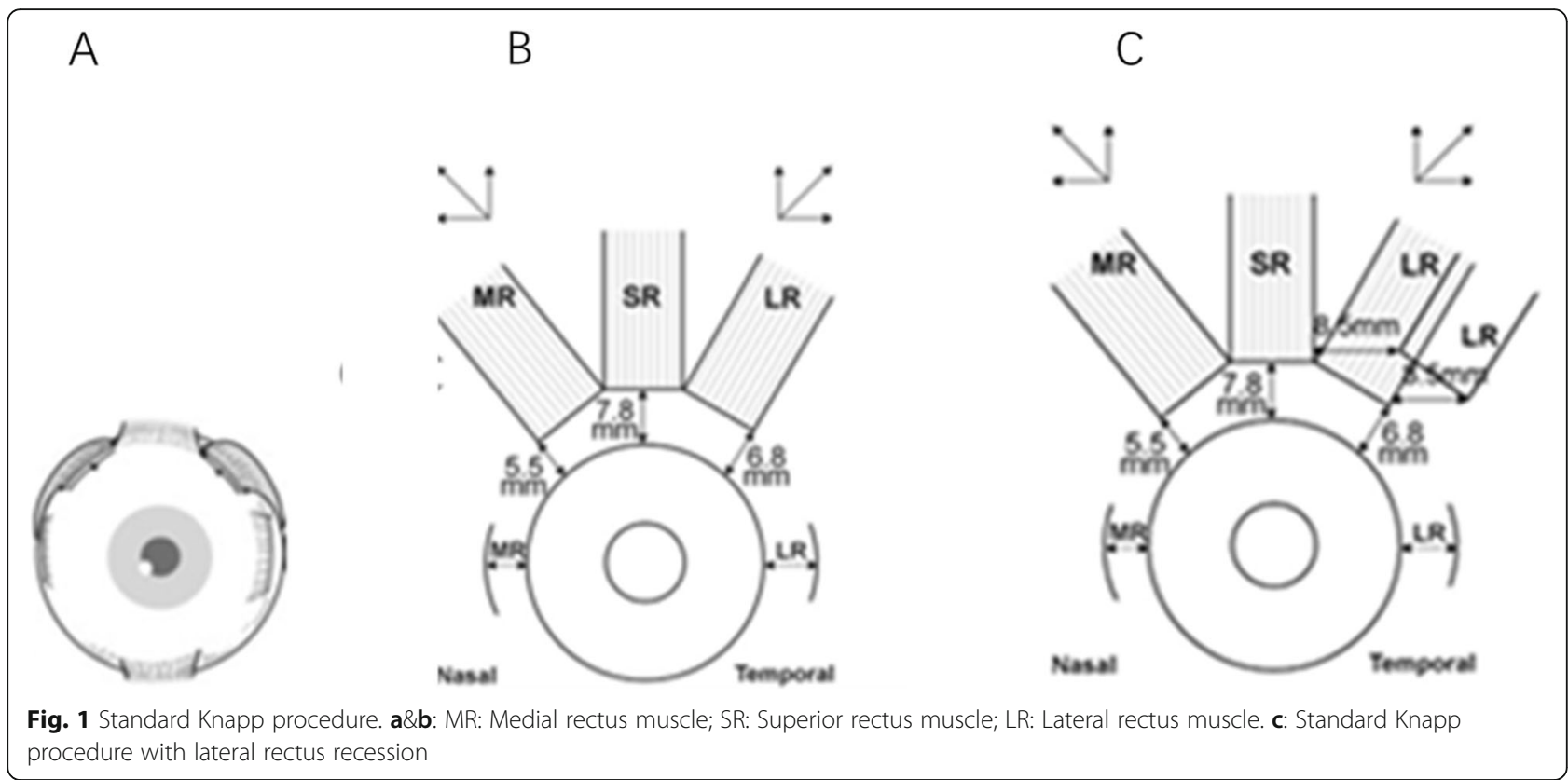

motility anomaly was recorded as +1 or more of muscle overaction and -1 or more of under-action. FDT was performed after general anaesthesia using a nondepolarizing muscle flaccidity in all MED patients.

We analysed the ocular alignment and elevation improvement. The criterion of success was defined as a residual vertical squint $\leq 10 \mathrm{PD}$ and $\geq 1$ overaction or under-action improvement after the surgery. The follow-up ranged from 1 to 12 months (median 3.5 months).

\section{Statistical analysis}

Statistical analysis was performed using IBM SPSS Statistics version 21 . The variables, where appropriate, are reported as the mean and standard deviation. The two parameters of pre-operation and post-operation vertical deviation in MED patients were normally distributed, performed by applying the parametric paired sample $\mathrm{T}$ test. A non-parametric Wilcoxon signed-rank test was used to pairwise compare between the pre-operative and post-operative values. A $P$ value of $<0.05$ was considered significant.

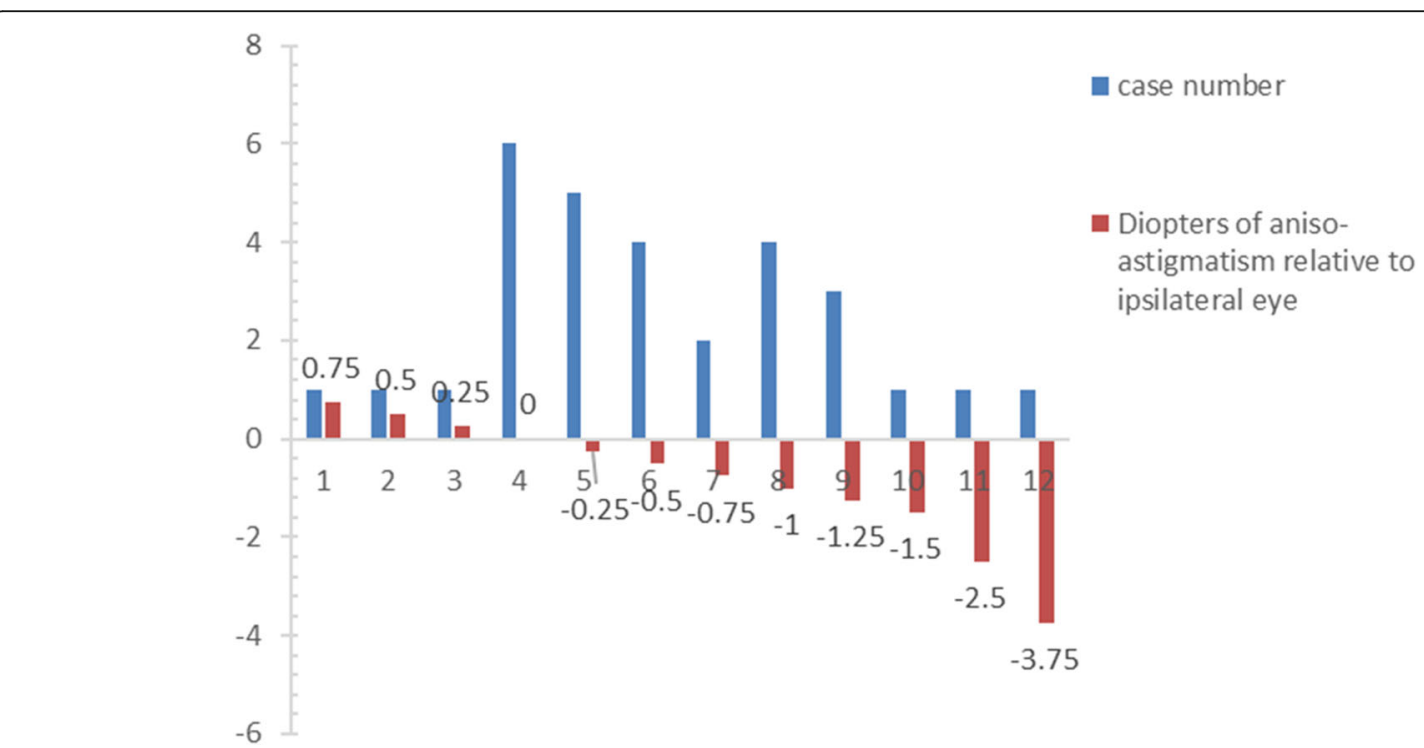

Fig. 2 Histogram showing aniso-astigmatism at the last recorded refraction for each patient. Negative numbers indicate more astigmatism on the contralateral side to the synostosis 
Table 1 Refractive dioptres and ophthalmic problems before strabismus surgery

\begin{tabular}{|c|c|c|c|c|c|c|}
\hline Case No. & Sex & Age & Ophthalmic Diagnosis & Unilateral Coronal Synostosis & OD Refraction & OS Refraction \\
\hline 1 & female & $\begin{array}{l}2 \mathrm{y} \\
3 \mathrm{mos}\end{array}$ & LMED & right & $+0.75-1.25^{*} 180$ & $+3.00-2.50 * 180$ \\
\hline 2 & male & $\begin{array}{l}1 \mathrm{y} \\
7 \mathrm{mos}\end{array}$ & LMED & right & $+2.50-1.25^{*} 180$ & $+3.25-1.75^{*} 180$ \\
\hline 3 & male & $\begin{array}{l}2 \mathrm{y} \\
7 \mathrm{mos}\end{array}$ & LMED & right & $+3.50-2.00 * 155$ & $+1.75-3.00 * 175$ \\
\hline 4 & male & $\begin{array}{l}1 y \\
10 \text { mos }\end{array}$ & LMED & right & $-1.00-0.50 * 165$ & $-2.25-0.50^{*} 135$ \\
\hline 5 & female & $2 y$ & Cong ET & right & $+4.25-1.25^{*} 140$ & $+4.75-0.50 * 165$ \\
\hline 6 & male & $\begin{array}{l}5 \mathrm{y} \\
2 \mathrm{mos}\end{array}$ & LMED\& IXT & right & 0 & 0 \\
\hline 7 & male & $\begin{array}{l}4 \mathrm{y} \\
4 \mathrm{mos}\end{array}$ & LSOP\&R trichiasis & left & $+2.25-1.50 * 20$ & $+1.00-0.50 * 180$ \\
\hline 8 & male & $2 y$ & CXT & left & $-0.50-0.25^{*} 145$ & 0 \\
\hline 9 & male & $7 \mathrm{mos}$ & IXT & right & $+2.00-0.33 * 59$ & $+2.50-1.33 * 179$ \\
\hline 10 & male & $9 \mathrm{mos}$ & & right & $+0.75-1.00^{*} 160$ & $+1.00-1.50 * 30$ \\
\hline 11 & male & $3 \mathrm{mos}$ & & right & $+0.75-1.25 * 15$ & $+1.00-2.50 * 5$ \\
\hline 12 & female & $6 \mathrm{mos}$ & LMED & right & $+0.50-0.75^{*} 180$ & $+1.00-1.00 * 180$ \\
\hline 13 & female & $\begin{array}{l}4 y \\
6 \text { mos }\end{array}$ & & right & $+2.25-0.25^{*} 180$ & $+2.50-1.50^{*} 180$ \\
\hline 14 & male & $\begin{array}{l}2 \mathrm{y} \\
1 \mathrm{mo}\end{array}$ & & left & $+3.50-4.50 * 11$ & $+0.50-0.75 * 5$ \\
\hline 15 & female & $\begin{array}{l}1 \mathrm{y} \\
2 \mathrm{mos}\end{array}$ & & right & $+0.50-1.75^{*} 180$ & $+0.50-1.75^{*} 180$ \\
\hline 16 & male & $\begin{array}{l}5 \text { mos } \\
4 \mathrm{~d}\end{array}$ & & right & $+0.50-0.50^{*} 180$ & $-1.25^{*} 180$ \\
\hline 17 & male & $\begin{array}{l}1 \mathrm{y} \\
7 \mathrm{mos}\end{array}$ & & right & $+0.25-0.50^{*} 180$ & $+0.75-3.00 * 180$ \\
\hline 18 & female & $8 \mathrm{mos}$ & LMED & right & $+0.50-0.75^{*} 180$ & $+0.50-0.50 * 180$ \\
\hline 19 & female & 10 mos & LCLDO & right & $+0.75-0.50 * 180$ & +0.75 \\
\hline 20 & female & 20 mos & & right & 0 & +0.25 \\
\hline 21 & female & 9 mos & & right & $+0.25-0.25^{*} 132$ & $+0.50-0.50 * 74$ \\
\hline 22 & male & $\begin{array}{l}1 \mathrm{y} \\
3 \mathrm{mos}\end{array}$ & & right & +0.25 & $+0.25-1.00^{*} 180$ \\
\hline 23 & female & $\begin{array}{l}4 y \\
7 \text { mos }\end{array}$ & VXT & left & $+2.00-1.00 * 5$ & $+1.25-0.50 * 2$ \\
\hline 24 & male & $\begin{array}{l}2 \mathrm{y} \\
6 \mathrm{mos}\end{array}$ & VXT & left & $-0.50-0.25^{*} 145$ & 0 \\
\hline 25 & female & $5 y$ & VXT & right & $-0.25-0.50^{*} 110$ & $+1.50-0.75 * 5$ \\
\hline 26 & female & $\begin{array}{l}3 \mathrm{y} \\
2 \mathrm{mos}\end{array}$ & LSOP\&IXT & left & $+1.00-0.75^{*} 180$ & $+1.25-0.75^{*} 180$ \\
\hline 27 & female & $\begin{array}{l}3 \mathrm{y} \\
1 \mathrm{mo}\end{array}$ & VXT & left & $+3.25-1.75 * 43$ & $+2.50-0.25^{*} 153$ \\
\hline 28 & male & $\begin{array}{l}2 y \\
8 \text { mos }\end{array}$ & RMED & left & $+1.00-1.25^{*} 180$ & $+1.00-0.50 * 180$ \\
\hline 29 & male & $6 y$ & VET & right & $+1.50-0.75 * 90$ & $+0.75-0.75^{*} 180$ \\
\hline 30 & male & $5 y$ & VXT & left & $+2.00-0.75^{*} 175$ & $+1.25-0.25 * 150$ \\
\hline
\end{tabular}

LMED left MED, Cong ET congenital esotropia, IXT intermittent exotropia, CXT constant exotropia, LSOP left superior oblique palsy, VXT V pattern exotropia, VET V pattern esotropia, $L C L D O$ left congenital lacrimal duct obstruction 
Table 2 Axes of astigmatism at the last recorded refraction for eyes ipsilateral and contralateral to the suture

\begin{tabular}{lll}
\hline & Eye numbers & \\
\cline { 2 - 3 } & Ipsilateral & Contralateral \\
\hline With the rule & 17 & 22 \\
Against the rule & 2 & 3 \\
Oblique & 6 & 2 \\
No astigmatism & 5 & 3 \\
\hline
\end{tabular}

\section{Results}

Refractive errors of thirty UCS patients were included in the study. A total of $43.3 \%$ (13/30) were female, and $70 \%$ $(21 / 30)$ had a right-sided UCS. The median age at the last recorded refraction was 1.8 years (range, 3.3 months to 6 years). Sixty percent (18/30) of patients had $1.00 \mathrm{D}$ or more astigmatism in not less than one eye at their last recorded refraction. Ten of the $18(55.6 \%)$ had anisoastigmatism of $1.00 \mathrm{D}$ or more. Of these 18 patients, 8
(44.4\%) had higher (1.00 D or more) astigmatism in the contralateral eye. Twenty of $30(66.7 \%)$ patients had higher $(0.25 \mathrm{D}$ or more) astigmatism in the contralateral eye, while the other 3 patients had higher astigmatism in the ipsilateral eye, with aniso-astigmatism less than 1.00 D. The aniso-astigmatism of 30 patients is demonstrated in Fig. 2.

Table 1 shows the refraction error and ophthalmic problems in all eyes before strabismus surgery. Table 2 shows the axes of astigmatism. In both ipsilateral eyes and contralateral eyes, astigmatism was found most frequently 'with the rule'; nevertheless, some likewise represented oblique axes. Spherical anisometropia may cause amblyopia, which was also calculated for each patient's last refraction record. Five patients had not less than $1.00 \mathrm{D}$ spherical anisometropia.

Because UCS children have a high incidence of strabismus and refractive error, we called them back to the ophthalmology clinic for a regular eye examination for refraction and ocular alignment half a year after UCS

Table 3 Pre- and post-operative evaluations

\begin{tabular}{|c|c|c|c|c|c|c|c|c|c|c|c|}
\hline \multirow{2}{*}{$\begin{array}{l}\text { Case } \\
\text { No. }\end{array}$} & \multirow[t]{2}{*}{ Age } & \multirow[t]{2}{*}{ Eye position } & \multicolumn{4}{|c|}{ Deviation (PD) } & \multirow{2}{*}{ Procedure } & \multicolumn{3}{|c|}{ Elevation deficiency } & \multirow{2}{*}{$\begin{array}{l}\mathrm{F} / \mathrm{U} \\
\text { (mo.) }\end{array}$} \\
\hline & & & Pre-op. & $\begin{array}{l}\text { Post- } \\
\text { op. }\end{array}$ & Correction & UCS & & Pre-op. & $\begin{array}{l}\text { Post- } \\
\text { op. }\end{array}$ & Correction & \\
\hline 1 & $\begin{array}{l}2 \text { y } 3 \\
\text { mos }\end{array}$ & OS hypo & $\begin{array}{l}-30 R / \\
\text { L25 }\end{array}$ & 0 & 25 & $\mathrm{R}$ & Left Knapp & $2-$ & 0 & 2 & 12 \\
\hline 2 & $\begin{array}{l}4 \text { y } 4 \\
\text { mos }\end{array}$ & OS hypo & $\mathrm{L} / \mathrm{R} 20$ & 0 & 20 & L & $\begin{array}{l}\text { LIOA+R lower eyelid } \\
\text { trichiasis }\end{array}$ & $\mathrm{LIOO} 2+$ & 0 & 2 & 5 \\
\hline 3 & $\begin{array}{l}5 \text { y } 2 \\
\text { mos }\end{array}$ & OS hypo & $\begin{array}{l}-40 R / \\
L 20\end{array}$ & 0 & 20 & $\mathrm{R}$ & Left Knapp RLRR+LLRR & $2-$ & 0 & 2 & 4 \\
\hline 4 & $\begin{array}{l}2 \text { y } 7 \\
\text { mos }\end{array}$ & OS hypo & $R / L 30$ & 0 & 30 & $\mathrm{R}$ & Left Knapp & $2-$ & 0 & 2 & 2 \\
\hline 5 & $\begin{array}{l}1 \text { y } 7 \\
\text { mos }\end{array}$ & OS hypo & $\mathrm{R} / \mathrm{L} 30$ & 0 & 30 & $\mathrm{R}$ & Left Knapp & $2-$ & 0 & 2 & 2 \\
\hline 6 & $\begin{array}{l}\text { ly } 10 \\
\text { mos }\end{array}$ & OS hypo & $R / L 30$ & 5 & 25 & R & Left Knapp & $2-$ & $1-$ & 1 & 7 \\
\hline 7 & $2 y$ & esotropia & 80 & 0 & 80 & $\mathrm{R}$ & RMRR+LMRR & 0 & 0 & 0 & 3 \\
\hline 8 & $2 y$ & exotropia & -50 & 0 & 50 & L & RLRR+LLRR & 0 & 0 & 0 & 6 \\
\hline 9 & $\begin{array}{l}2 \text { y } 6 \\
\text { mos }\end{array}$ & $\begin{array}{l}V \text { pattern } \\
\text { exotropia }\end{array}$ & -80 & 0 & 80 & L & $\mathrm{RLRR}+\mathrm{LLRR}+\mathrm{IOA}$ & $\mathrm{LIOO4+RIOO+}$ & 0 & R4 L1 & 1 \\
\hline 10 & $5 y$ & $\begin{array}{l}V \text { pattern } \\
\text { exotropia }\end{array}$ & -15 & 0 & 15 & $\mathrm{R}$ & $\mathrm{RIOA}+\mathrm{LIOA}$ & $\mathrm{RIOO} 3+\mathrm{LIOO} 2+$ & $\mathrm{RIOO1+}$ & R2L2 & 3 \\
\hline 11 & $\begin{array}{l}3 \text { y } 2 \\
\text { mos }\end{array}$ & $\begin{array}{l}\text { OS hyper } \\
\text { exotropia }\end{array}$ & -35 & -5 & 30 & L & RLRR+LLRR+LIOA & $\mathrm{LIOO} 2+$ & 0 & 2 & 7 \\
\hline 12 & $4 y$ & $\begin{array}{l}V \text { pattern } \\
\text { exotropia }\end{array}$ & -40 & 0 & 40 & L & $R L R R+R I O A+L L R R+L I O A$ & $\mathrm{RIOO} 1+\mathrm{LIOO} 1+$ & 0 & 1 & 7 \\
\hline 13 & 2 y $8 \mathrm{mo}$ & OS hyper & $\mathrm{L} / \mathrm{R} 20$ & $R / L 10$ & 20 & L & Right Knapp & $2-$ & $1+$ & 3 & 7 \\
\hline 14 & $6 y$ & $\begin{array}{l}\vee \text { pattern } \\
\text { esotropia }\end{array}$ & 15 & 0 & 15 & $\mathrm{R}$ & LMRR+RIOA+LIOA & $\mathrm{RIOO} 2+\mathrm{LIOO} 2+$ & 0 & 2 & 1 \\
\hline 15 & $5 y$ & $\begin{array}{l}V \text { pattern } \\
\text { exotropia }\end{array}$ & -60 & 0 & 60 & L & $\mathrm{LLRR}+\mathrm{RIOA}+\mathrm{LIOA}$ & $\begin{array}{l}\mathrm{RlOO} 2+ \\
\mathrm{LIOO} 4+\end{array}$ & LIOO1+ & R2L3 & 3 \\
\hline
\end{tabular}

PD Prism dioptre, Hypo Hypotropia, HYPER Hypertropia, RLRR Right lateral rectus recession, $L L R R$ Left lateral rectus, RMRR Right medial rectus recession, $L M R R$ Left medial rectus recession, $L I O O$ Left inferior oblique overaction, IOA inferior oblique anteriorization. Bell's sign was positive in all patients. FDT was negative in all six MED patients 
surgery. We have listed the last refraction values before the strabismus surgery in Table 1.

Among the 30 UCS patients, 15 strabismus patients underwent surgery, including 6 with contralateral MED, 1 with exotropia, 2 with unilateral superior oblique palsy, 5 with $\mathrm{V}$ pattern deviation (bilateral superior oblique palsy) and 1 with esotropia. Observations of the horizontal or vertical squint and elevation deficiency or overaction were compared pre- and post-operatively, as shown in Table 3. We also surveyed age, ocular alignment, coronal synostosis, operation and follow-up periods (Table 3).

We checked the vertical squint pre-operatively, at the time of surgery and post-operatively in MED patients. All three parameters were normally distributed, indicating that parametric tests could be used.

In six MED patients, the vertical squint was diminished in the primary position from $25.83 \Delta \pm 4.92 \Delta$ (range, $20 \Delta$-30 $\Delta$ ) to $0.83 \Delta \pm 4.92 \Delta$ after surgery (range, $0 \Delta-10 \Delta$ ), for an improvement of $26.67 \Delta \pm 4.08$ $\Delta(\mathrm{t}=16 P<0.05)$.

The elevation deficiency improved from -2 to $0(0.50)$ for an improvement of 2 (0.50) units post-operatively $(Z=2.264 P<0.05)$. Of these 15 strabismus patients, $5 \mathrm{~V}$ patterns and 2 superior oblique palsy patients showed vertical deviation. Elevation overaction is probably overaction of the inferior oblique. The elevation overaction improved from $+2(1.5)$ to 0 after surgery for an improvement of $2(0.75)$ units. $(Z=-3.133 P=0.002)$.

The details of elevation deficiency changes pre- and post-operatively are shown in each case (Fig. 3).

Six patients were diagnosed with MED, in whom the FDT was negative and Bell's sign was positive. In the six patients, the sound eye was dominant. The other 2 patients had ipsilateral inferior oblique palsy, one of them with contralateral trichiasis, 4 with $\mathrm{V}$ pattern exotropia,
1 with $\mathrm{V}$ pattern esotropia, one with esotropia, and one with exotropia. At the follow-up visit after surgery, all 15 strabismus operations (100\%) succeeded.

A right UCS patient aged 1 years and 7 months showed deficient elevation of the left eye in both adduction and abduction pre-operatively (Fig. 4a). The elevation deficiency had improved in one day after the Knapp procedure (Fig. 4b). At the one-month and one-year follow-ups after the operation, the elevation deficiency had improved significantly compared with that in the pre-operative period. The follow-up period lasted 1 year (Fig. 4c \& d).

Figure $5 \mathrm{a} \& \mathrm{~b}$ \&c shows malformation of the UCS obit, recession and elevation of the ipsilateral superior orbital rim. One right UCS skull before the craniotomy is shown in Fig. $5 \mathrm{a} \& \mathrm{~b}$. The craniofacial malformation was caused by premature closure of the right coronal suture.

The skull malformation of the child with right UCS is shown in Fig. 6a. After craniofacial surgery, the frontal bone shifted forward. Figure $6 \mathrm{~b}$ Cerebral magnetic resonance imaging of the right UCS shows an asymmetric brain, with the ipsilateral hemisphere significantly smaller than the contralateral hemisphere.

Many doctors cannot recognize UCS. The child who had right UCS with $\mathrm{V}$ pattern esotropia underwent craniofacial reconstruction until half a year ago, when he was already more than 5 years old. His skull was obviously asymmetrical (Fig. 7a). He had undergone bilateral medial rectus recession and inferior oblique anteriorization procedures when he was 6 years old. We successfully corrected the horizontal and vertical deviations simultaneously. Overaction elevation of both eyes was shown preoperatively in adduction (Fig. 7b). By the 1-month follow-up after strabismus surgery, the elevation overaction had recovered (Fig. 7c). The follow-up

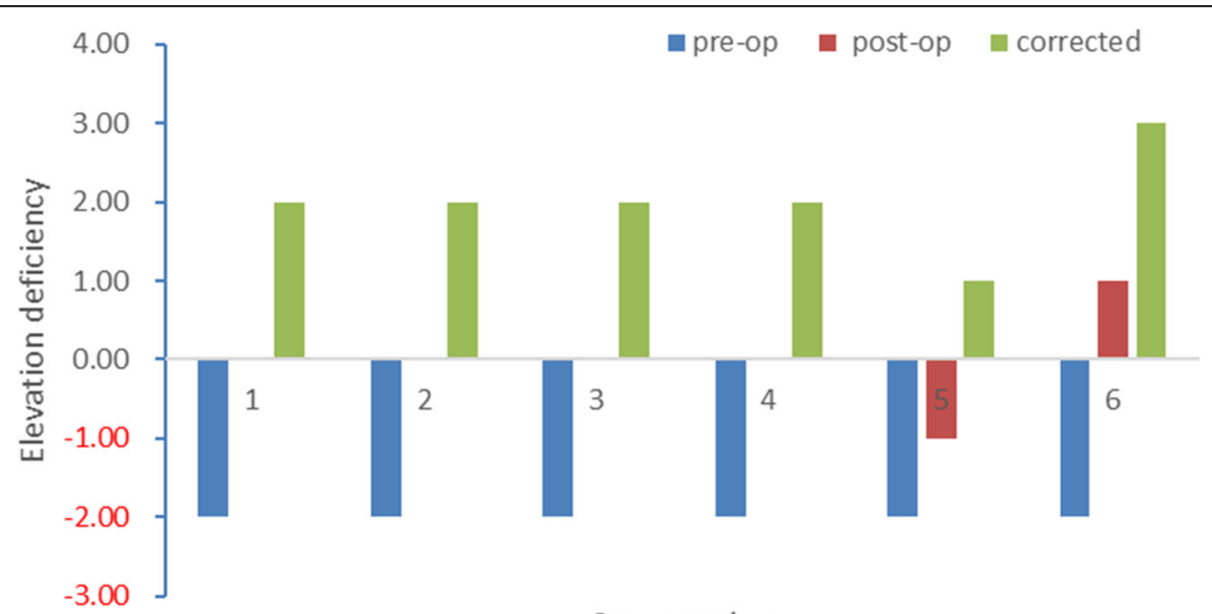

Case number

Fig. 3 The corrected elevation deficiency changes pre- and post-operatively in six double elevator palsy cases 


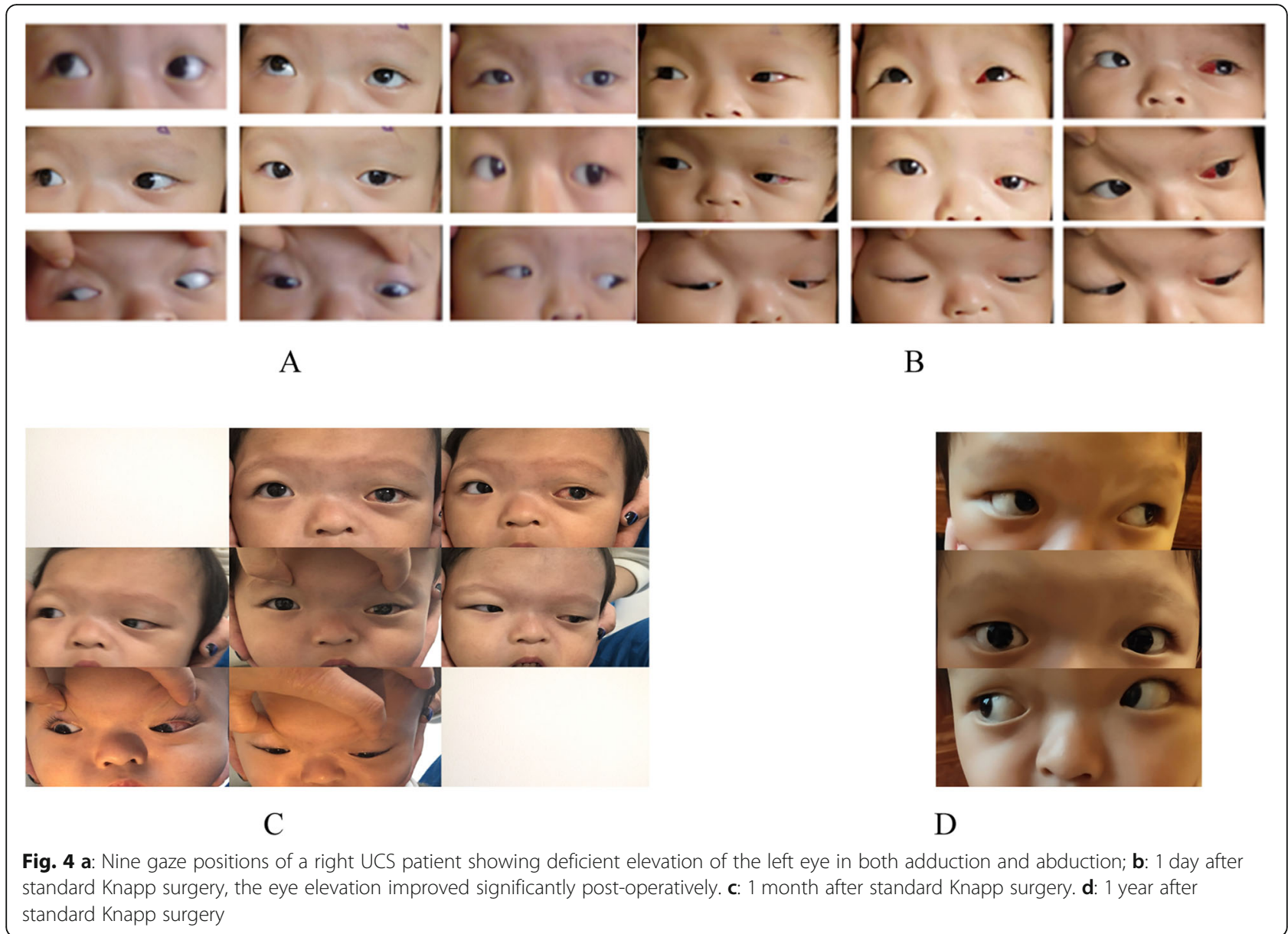

periods lasted for 1 month. No obvious complications occurred after strabismus surgery.

\section{Discussion}

Premature closure of one of the cranial sutures results in a restricted growth pattern across the fused suture, while a compensatory or accelerated growth pattern typically occurs parallel to the affected synostosis [7]. Fibroblast growth factor receptor (FGFR) mutations are most frequently cited in association with craniosynostosis, especially syndromic types. A single genetic anomaly has still not been identified as a cause for craniosynostosis [8].

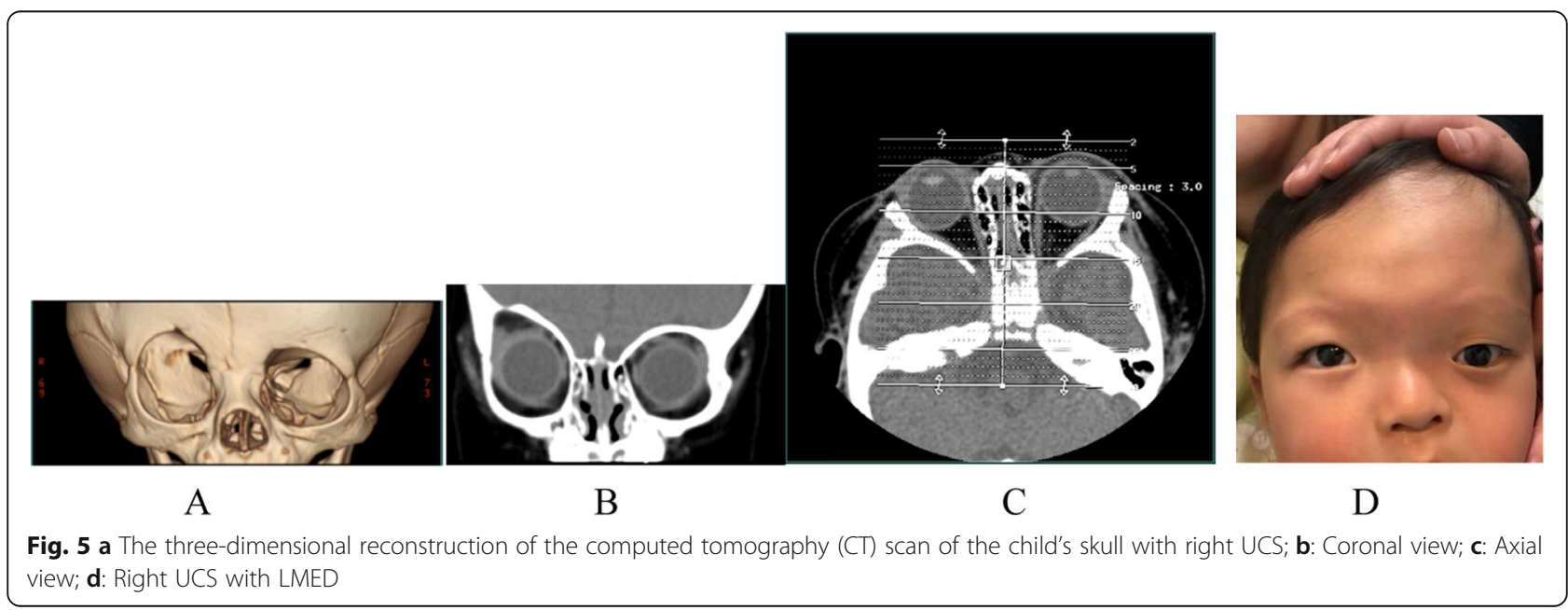




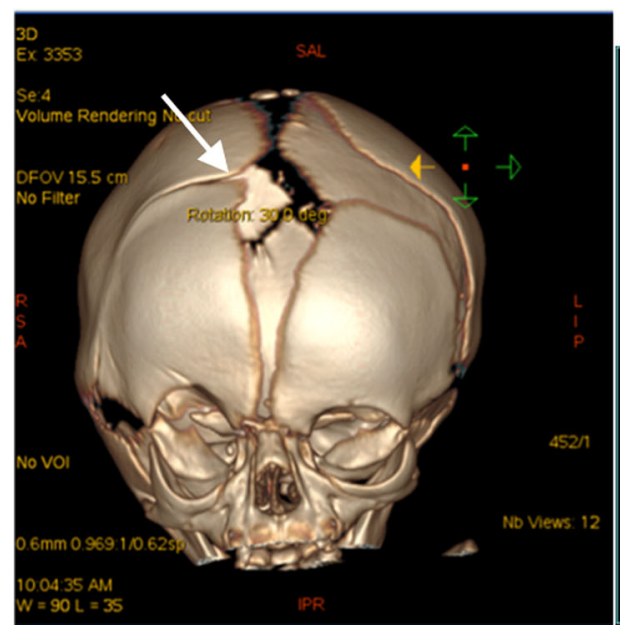

A

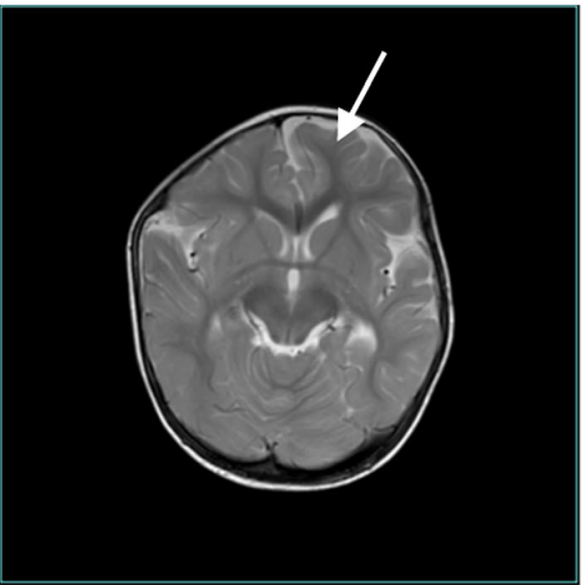

B

Fig. 6 a Three-dimensional reconstruction of a computed tomography (CT) scan of a child's skull with right UCS after craniofacial surgery. The white arrowhead refers to the right coronal synostosis. 7-b: Cerebral magnetic resonance imaging of another child with right UCS

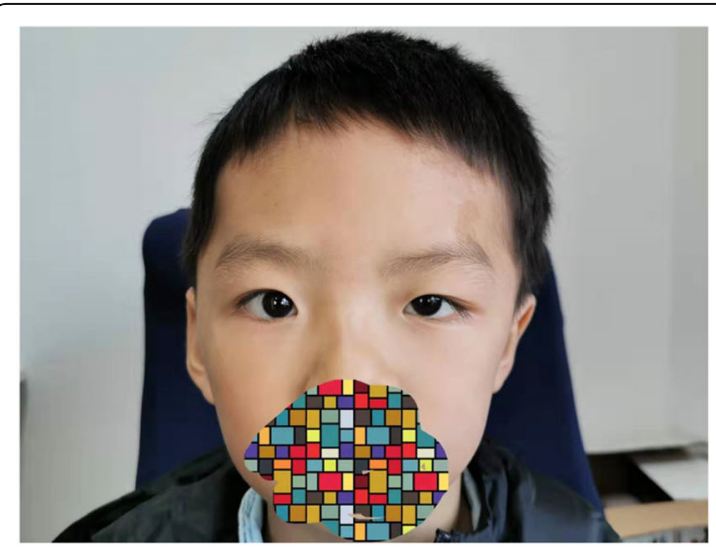

A
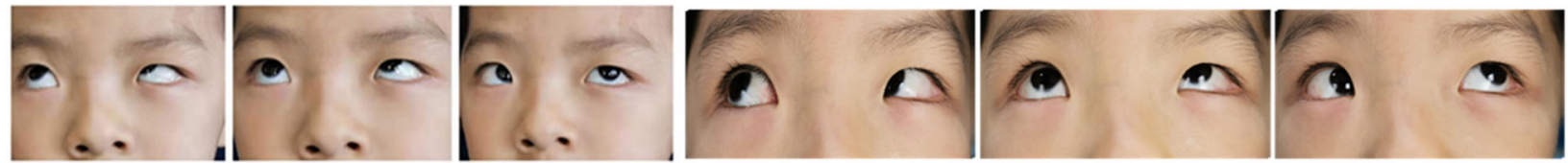

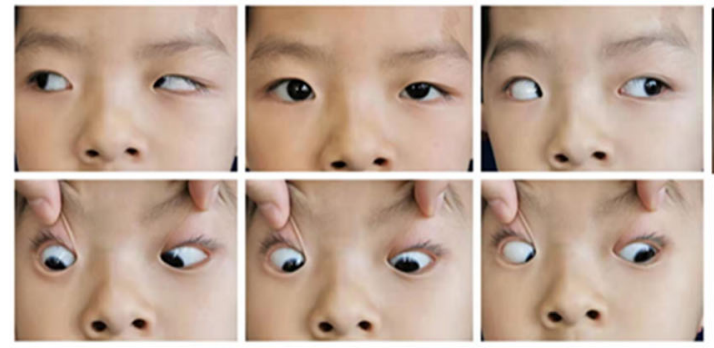

B

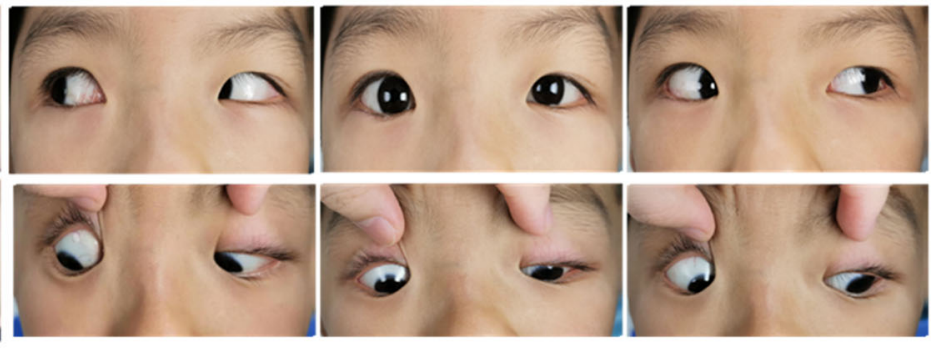

$\mathrm{C}$

Fig. 7 a: A six-year-old right UCS patient with esotropia V pattern strabismus. b: Overaction elevation of both eyes is shown in adduction preoperatively; c: 1 month after surgery, the eye overaction elevation was recovered significantly post-operatively 
UCS children usually present with the characteristic signs involving the ipsilateral side: (1) Flattening of the forehead and a shallow orbit, resulting in an ipsilateral increased vertical diameter; and (2) tilting of the head as a compensatory mechanism resulting from both the extraocular muscle imbalance [9]. UCS not only affects one coronal suture but also affects orbital skeletal development. There are many disorders, including eyelid anomalies, ptosis and trichiasis, strabismus, proptosis, and refractive error [10]. Many patients experience severe forms of the disease, causing a significant impact on their quality of life. We treated all ophthalmic complications after cranioplastic surgery [11], even after fronto-orbital advancement (FOA) [12], although many reports summarize that FOA does not seem to shorten rates of strabismus $[4,10]$.

There is a great difference between healthy children and children with UCS in the prevalence of strabismus. Chen et al [13] reported that the prevalence of strabismus in a population-based sample of preschool children aged 36-72 months in eastern China was $5.65 \%$ (95\% CI 5.05 to $6.25 \%$ ). Intermittent exotropia was the most common type of strabismus among all children (57.81, 95\% CI 49.48 to $66.14 \%$ ); however, pure vertical strabismus was unusual (3.13\%). Matsuo [14] et al reported that the prevalence of strabismus was $1.28 \%$ (95\% CI 1.24 to $1.36 \%$ ) in Japanese elementary school children, and the prevalence rates of any types of exotropia and esotropia were 0.69 and $0.28 \%$, respectively.

In this investigation, there were 9 cases of simple strabismus and 6 cases of complex strabismus with other ocular complications. Strabismus patients included 6 with contralateral MED, 5 with $\mathrm{V}$ pattern strabismus, 1 with exotropia, 1 with esotropia and 2 with superior oblique palsy. We found that vertical deviation was more common than exotropia, possibly due to an abnormal orbital bone.

One patient with trichiasis underwent a trichiasis procedure. One patient with contralateral congenital lacrimal duct obstruction underwent a probing operation.

Due to a young age, 1 child with strabismus had not been offered strabismus surgery. One 5-month-old patient with right UCS showed $40 \Delta$ esotropia deviation and hypermetropia of 5.00 dioptres in both eyes. Fully correcting refractive error and occlusion is the initial treatment. We will await a good opportunity for the procedure.

Both UCS and double elevator palsy are rare diseases. Contralateral MED was also the main type of strabismus in UCS. Superior oblique muscle palsy was still the most common as previously reported (74-100\%) [10], and the ipsilateral eye was more frequently involved ( $\geq 32$ to $100 \%$ ) [10]. Nischal speculated that changes in the orbital shape and axes changed the oblique muscle insertions on the synostotic side, mimicking superior oblique paresis and thus creating hypertropia (manifesting as a deviation of one eye in an upward direction). Additionally, the trochlea is displaced for the orbital rotation and relative recession of the frontal process in UCS, causing a change in the angle through which the superior oblique turns, creating a mechanical disadvantage for its action [15]. Some studies have reported a predominance of esotropia $(60-100 \%)[4$, 16-18] and exotropia (36\%) [19] in their patient populations. Our paper is the first to discuss MED in UCS; strabismus surgery must be performed after craniofacial reconstruction because reducing intracranial pressure is the most important treatment for saving lives. The hypotropia in the primary position is contralateral to the affected synostosis and increases in elevated gaze (adduction and abduction), with apparent under-action of the contralateral inferior oblique and superior rectus muscles. Therefore, hypotropia is treated in a surgically similar manner to routine MED. MED is defined as the inability to elevate one eye equally in abduction, adduction, caused by paralysis of the superior rectus and inferior oblique [20]. Knapp [21] created the traditional Knapp procedure (Fig. 1a). Because of the rotation of the eye caused by the traditional procedure, we adopted the standard Knapp procedure: the medial rectus and lateral rectus muscles were transposed superiorly to the insertion of the superior rectus muscle (Fig. 1a \& b). We reported the management of double elevator palsy patients with standard Knapp procedures or augmented Knapp procedures in 2018 [22].

Many reports support ipsilateral retrusion of the forehead and elevation of the superior orbital margin; with widening of the palpebral fissure; the contralateral side develops compensatory bossing of the forehead and narrowing of the palpebral fissure $[2,6]$. Joel [23] provided evidence that both orbits in UCS patients are dysmorphic. The ipsilateral orbit is tall and narrow in morphology and smaller in volume, whereas the contralateral side is vertically short and wide in morphology and larger in volume. This contrasts with unaffected individuals who have a good deal of orbital symmetry in both volume and morphology. As orbital asymmetry may form the basis for many of the ocular abnormalities associated with UCS, bilateral orbit reconstruction should be considered. We propose two hypotheses about MED. First, the FGFR mutation may lead to deformation of the extraocular muscle (EOM) and orbital shape. Second, we hypothesize that the skull deformation and orbital deformation results in changes in muscle active road and strength. We have chosen to obtain evidence of anatomical support in the near future.

According to the latest technology, even 3D images cannot provide obvious evidence to support our hypothesis. In all UCS cases, we found no deformation of 
EOM, unlike Crouzon or Pfeiffer syndrome. EOM insertion dislocation, lack of muscle, and weak musculature always exist in Crouzon or Pfeiffer syndrome. Although we found no abnormalities in the pulley and muscles of the contralateral eye, we speculated that contralateral dysmorphic orbit or unilateral supranuclear lesions in the pretectal area near or inside the third cranial nerve nucleus [24] may cause MED.

$\mathrm{V}$ pattern exotropic strabismus is common in patients [25] with craniofacial dysostosis, with as many as twothirds of patients manifesting the condition, which is similarly common in UCS patients. This is our first report on the management of $\mathrm{V}$ pattern horizontal strabismus in UCS.

Many papers have discussed the long-term visual outcomes after craniofacial surgery in all kinds of craniosynostosis [26-29], and few papers have shared experience with lid abnormalities in cases of craniosynostosis.

Because of apoptosis and the lesser amount of orbital fat pad, trichiasis in the lower lid always reduces the quality of life in UCS, which hurts the cornea leading to photophobia, red eye, and tilt head position. The Hotz method was adopted, and we removed a strip of skin and orbicularis oculi muscle and sutured the skin with the lower tarsus. Tarsus in children with craniosynostosis was thinner than normal. Therefore, scar tissue was the main strength of ectropion. Surgeons must be careful to suture the thin tarsus preventing perforation, and a 6-0 absorbable suture is our first choice.

Many papers have focused on the treatment of refractive errors and amblyopia. In our papers, we found a considerably high occurrence of astigmatism in the contralateral eye. Richard et al [30] speculated that this is caused by the inferior displacement of the superior orbital margin and roof, which possibly impacts the corneal curvature; the slightly increased globe volume may exacerbate this phenomenon.

\section{Conclusions}

UCS is a complex disorder, and management requires coordinated effort from a multidisciplinary team. Contralateral MED was also the main type of strabismus in UCS. Superior oblique muscle palsy was still the most common, as previously reported. The vertical deviation was less than $30 \mathrm{PD}$ in all MED patients, so we performed a standard Knapp procedure. We performed inferior oblique muscle anteriorization to correct superior oblique palsy and achieved success in all strabismus surgeries. Patients are at risk for developing a greater degree of astigmatism and anisometropia in the eye contralateral to the synostosis. Saving eyesight and recovering visual function are the goals of all interventions after all surgeries, correcting refractive errors and training amblyopia in the long-term period. Other ocular disorders should be treated in a timely manner.

\section{Supplementary information}

Supplementary information accompanies this paper at https://doi.org/10. 1186/s12886-020-01547-1.

\section{Additional file 1}

\section{Abbreviations}

UCS: Unilateral coronal synostosis; MED: Monocular elevation deficiency; FDT: Forced duction test; FOA: Fronto-orbital advancement; PD: Prism dioptre; Hypo: Hypotropia; HYPER: Hypertropia; LRR: Lateral rectus recession; MRR: Medial rectus recession; LIOM: Left inferior oblique muscle; LIOO: Left inferior oblique overaction; IOA: Inferior oblique anteriorization

\section{Acknowledgements}

None.

\section{Authors' contributions}

All authors contributed to the study and the revision of the manuscript. W-T $\mathrm{L}$ : Design of the study, text writing, design of tables and figures; $X \mathrm{C}$ : main data collection. Y-D Z: Statistical expertise. Q-Y L: text writing. T Q: data collection, critical revision of the manuscript and final approval. All authors have read and approved the manuscript in its current state. All authors declare their consent for publication. All authors read and approved the final manuscript.

\section{Funding}

Not applicable.

\section{Availability of data and materials}

Supporting data can be accessed by contact with the corresponding author (qiao joel@163.com)

The datasets analysed are available from the corresponding author upon reasonable request. We could provide the video of the operation.

\section{Ethics approval and consent to participate}

Ethics approval No. 2020R023-E01 was obtained on March 30, 2020. All procedures performed in the study were in accordance with the ethical standards of the institutional and/or national research committee and with the 1964 Helsinki Declaration and its later amendments or comparable ethical standards. Written consent for data processing was obtained from each patient's parents. Our study was approved by the Institutional Review Board of Shanghai Children's Hospital. For further questions, please contact the ethics committee at the following address: Shanghai Children's Hospital affiliated with Shanghai Jiao Tong University, Shanghai 200062, China, E-Mail: ertonglunli@126.com

\section{Consent for publication}

We can provide the video of the operation. The parents of the study participants gave written consent for their personal or clinical details along with any identifying images to be published in the study.

\section{Competing interests}

Not applicable.

Received: 2 December 2019 Accepted: 3 July 2020

Published online: 04 August 2020

\section{References}

1. Bartlett SP, Whitaker LA, Marchac D. The operative treatment of isolated craniofacial dysostosis (plagiocephaly): a comparison of the unilateral and bilateral techniques. Plast Reconstr Surg. 1990;85(5):677-83.

2. Bruneteau RJ, Mulliken JB. Frontal plagiocephaly: synostotic, compensational, or deformational. Plast Reconstr Surg. 1992;89(1):21-31 discussion 32-23.

3. Mackinnon S, Rogers GF, Gregas M, Proctor MR, Mulliken JB, Dagi LR. Treatment of unilateral coronal synostosis by endoscopic strip craniectomy 
or fronto-orbital advancement: ophthalmologic findings. J AAPOS. 2009; 13(2):155-60.

4. Lee SJ, Dondey J, Greensmith A, Holmes AD, Meara JG. The effect of frontoorbital advancement on strabismus in children with unicoronal synostosis. Ann Plast Surg. 2008;61(2):178-80.

5. Ganesh A, Edmond J, Forbes B, Katowitz WR, Nischal KK, Miller M, Levin A. An update of ophthalmic management in craniosynostosis. J AAPOS. 2019; 23(2):66-76.

6. MRE, CM. Craniosynostosis: diagnosis, evaluation and management, 2nd edn. New York: Oxford University Press; 2000.

7. Rosenberg JB, Tepper OM, Medow NB. Strabismus in craniosynostosis. J Pediatr Ophthalmol Strabismus. 2013;50(3):140-8.

8. Buchanan EP, Xue Y, Xue AS, Olshinka A, Lam S. Multidisciplinary care of craniosynostosis. J Multidiscip Healthc. 2017;10:263-70.

9. Luca M, Corcezio DR. Unilateral Coronal Craniosynostosis. Pediatric Neurosurgery. Springer Science and Business Media LLC. 2017:1-45.

10. Gencarelli JR, Murphy A, Samargandi OA, Bezuhly M. Ophthalmologic outcomes following Fronto-orbital advancement for Unicoronal Craniosynostosis. J Craniofac Surg. 2016;27(7):1629-35.

11. Nischal KK. The Clininal Management of Craniosynostosis. London: Mac Keith Press; 2004.

12. Hayward R, Gonsalez S. How low can you go? Intracranial pressure, cerebral perfusion pressure, and respiratory obstruction in children with complex craniosynostosis. J Neurosurg. 2005;102(1 Suppl):16-22.

13. Chen X, Fu Z, Yu J, Ding H, Bai J, Chen J, Gong Y, Zhu H, Yu R, Liu H. Prevalence of amblyopia and strabismus in eastern China: results from screening of preschool children aged 36-72 months. Br J Ophthalmol. 2016;100(4):515-9.

14. Matsuo T, Matsuo C. Comparison of prevalence rates of strabismus and amblyopia in Japanese elementary school children between the years 2003 and 2005. Acta Med Okayama. 2007;61 (6):329-34.

15. Nischal KK. Ocular aspects of craniofacial disorders. Am Orthopt J. 2002;52:58-68.

16. Denis D, Genitori L, Bolufer A, Lena G, Saracco JB, Choux M. Refractive error and ocular motility in plagiocephaly. Childs Nerv Syst. 1994;10(4):210-6.

17. Macintosh C, Wall S, Leach C. Strabismus in unicoronal synostosis: ipsilateral or contralateral? J Craniofac Surg. 2007;18(3):465-9.

18. Vasco G, Baranello G, Ricci D, Salerni A, Tamburrini G, Amante R, Dickmann A, Di Rocco C, Velardi F, Mercuri E. Longitudinal assessment of visual development in non-syndromic craniosynostosis: a 1-year pre- and postsurgical study. Arch Dis Child. 2008;93(11):932-5.

19. Diamond GR, Katowitz JA, Whitaker LA, Bersani TA, Bartlett SP, Welsh MG. Ocular and adnexal complications of unilateral orbital advancement for plagiocephaly. Arch Ophthalmol. 1987;105(3):381-5.

20. White JW. Paralysis of the superior rectus and the inferior oblique muscle of the same eye. Arch Ophthalmol. 1942;27(2):366-71.

21. Knapp P. The surgical treatment of double-elevator paralysis. Trans Am Ophthalmol Soc. 1969;67:304-23.

22. Luo WT, Qiao T, Ye HY, Li SH, Chen QL. Clinical features and surgical treatment of double elevator palsy in young children. Int J Ophthalmol. 2018;11(8):1352-7.

23. Beckett JS, Persing JA, Steinbacher DM. Bilateral orbital dysmorphology in unicoronal synostosis. Plast Reconstr Surg. 2013;131(1):125-30.

24. Jampel RS, Fells P. Monocular elevation paresis caused by a central nervous system lesion. Arch Ophthalmol. 1968;80(1):45-57.

25. Gobin MH. Sagittalization of the oblique muscles as a possible cause for the "a", "V", and "X" phenomena. Br J Ophthalmol. 1968;52(1):13-8.

26. Dagi LR, MacKinnon S, Zurakowski D, Prabhu SP. Rectus muscle excyclorotation and V-pattern strabismus: a quantitative appraisal of clinical relevance in syndromic craniosynostosis. Br J Ophthalmol. 2017;101(11):1560-5.

27. Nischal KK. Visual surveillance in craniosynostoses. Am Orthopt J. 2014:64:24-31.

28. Chung SA, Yun IS, Moon JW, Lee JB. Ophthalmic findings in children with nonsyndromic craniosynostosis treated by expansion cranioplasty. J Craniofac Surg. 2015;26(1):79-83.

29. Sharma N, Greenwell T, Hammerton M, David DJ, Selva D, Anderson PJ. The ophthalmic sequelae of Pfeiffer syndrome and the long-term visual outcomes after craniofacial surgery. J AAPOS. 2016;20(4):315-9.

30. Levy RL, Rogers GF, Mulliken JB, Proctor MR, Dagi LR. Astigmatism in unilateral coronal synostosis: incidence and laterality. J AAPOS. 2007;11(4):367-72.

\section{Publisher's Note}

Springer Nature remains neutral with regard to jurisdictional claims in published maps and institutional affiliations.

Ready to submit your research? Choose BMC and benefit from:

- fast, convenient online submission

- thorough peer review by experienced researchers in your field

- rapid publication on acceptance

- support for research data, including large and complex data types

- gold Open Access which fosters wider collaboration and increased citations

- maximum visibility for your research: over $100 \mathrm{M}$ website views per year

At BMC, research is always in progress.

Learn more biomedcentral.com/submissions 